\title{
Oxidation Stages of Aluminium Nitride Thin Films Obtained by Plasma-enhanced Chemical Vapour Deposition (PECVD)
}

\author{
N. Azema, ${ }^{a}$ J. Durand, ${ }^{a *}$ R. Berjoan, ${ }^{b}$ C. Dupuy ${ }^{b} \&$ L. $\operatorname{Cot}^{a}$ \\ ${ }^{a}$ Laboratoire de Physicochimie des Matériaux, URA 1312 du CNRS, 8 rue de l'Ecole Normale, \\ 34053 Montpellier Cédex 1, France \\ ${ }^{b}$ Institut de Science et de Génie des Matériaux et Procédés, BP 5, Odeillo, 66120 Font-Romeu, France
}

\begin{abstract}
Oriented (100) aluminium nitride thin films grown on silicon wafers (100) and other substrates, were deposited at $330^{\circ} \mathrm{C}$ by the metal-organic PECVD process. The oxidation behaviour in air of these films was studied at temperatures from $500^{\circ} \mathrm{C}$ to $1300^{\circ} \mathrm{C} \mathrm{by}$ $X$-ray diffiraction, scanning electron microscopy and Auger electron spectroscopy. Two textural changes occur: granular and porous textures at $900^{\circ} \mathrm{C}$ and $1100^{\circ} \mathrm{C}$, respectively. These correspond to the amorphous $\mathrm{Al}_{2} \mathrm{O}_{3}$ and the crystalline $\alpha$-alumina formation. Infra-red absorption spectroscopy show's that the oxidation effectively starts at $600^{\circ} \mathrm{C}$ and reveals an oxynitride phase between the amorphous $\mathrm{Al}_{2} \mathrm{O}_{3}$ coating which is formed, and the AlN remaining.
\end{abstract}

Durch ein MOPECVD-Verfahren wurden bei $330^{\circ} \mathrm{C}$ auf Siliziumscheiben (100) und anderen Substraten orientierte dünne Schichten aus AlN (100) abgeschieden. Das Oxidationsverhalten dieser Schichten in Luft wurde im Temperaturbereich von $500^{\circ} \mathrm{C}$ bis $1300^{\circ} \mathrm{C}$ durch XRD, REM und AES untersucht. Zwei Veränderungen im Gefüge bilden sich: eine körnige Schicht hei $900^{\circ} \mathrm{C}$ und eine poröse bei $1100^{\circ} \mathrm{C}$. Diese entsprechen dem amorphen $\mathrm{Al}_{2} \mathrm{O}_{3}$ und der $\alpha-\mathrm{Al}_{2} \mathrm{O}_{3}$ Kristallmodifikation. Infrarotabsorptionsspektroskopische Untersuchungen konnten zeigen, daß die Oxidation bereits bei $600^{\circ} \mathrm{C}$ beginnt und da $\beta=$ wischen dem sich bildenden amorphen $\mathrm{Al}_{2} \mathrm{O}_{3}$ Überzug und dem verbleibenden AlN eine Oxinitridphase vorliegt.

La croissance en couches minces de nitrure d'aluminium orienté (100), sur des plaquettes de silicium (100) et autres substrats, est obtenue à $330^{\circ} \mathrm{C}$

* To whom correspondence should be addressed. par MOPECVD. Le comportement à l'oxydation à l'air de ces films est étudié par diffraction des rayons $X$, microscopie electronique à balayage et spectroscopie des électrons Auger, à des températures allant de $500^{\circ} \mathrm{C}$ à $1300^{\circ} \mathrm{C}$. Deux changements de texture sont observés à $900^{\circ} \mathrm{C}$ et $1100^{\circ} \mathrm{C}$, conduisant respectivement à des couches de type granuleux et poreux, correspondant à la formation d'alumine amorphe et d'alumine $\alpha$ cristallisée. La spectroscopie d'absorption infra-rouge met en évidence un début d'oxydation à $600^{\circ} \mathrm{C}$ ainsi que la présence d'un oxynitrure d'aluminium entre la couche d'alumine amorphe et le nitrure d'aluminium non transformé.

\section{Introduction}

The wide field of aluminium nitride applications varies from dielectric to refractory compounds. It can be used as insulator in modern integrated circuits and is promising for optical uses because of its large energy band gap and masking ability. ${ }^{1,2}$ It is also an excellent substrate combining high thermal conductivity with high electrical resistivity for temperature-sensitive electronic components. ${ }^{3{ }^{34}}$ It is applied in surface acoustic wave (SAW) techniques ${ }^{5}$ for its piezoelectric properties and high acoustic velocity. The passivation properties (for example in semiconductor devices for surface passivation or as diffusion $\operatorname{masks}^{6}$ ) and oxidation resistance ${ }^{7}$ have been the subject of recent papers. On the other hand, it appears that the humidity tolerance of AIN is a debatable point in the scientific community.

In recent years, the high-temperature protection of materials by ceramics, well known for their thermomechanic properties and chemical resistance, has attracted considerable interest. AlN may be a 
good candidate; nevertheless, few studies deal with the oxidation behaviour of AIN powder, bulk and thin films. ${ }^{8-11}$ A surface chemistry model has been written $^{9}$ in which a gradual oxynitride layer $(5-10 \mathrm{~mm})$, formed on the surface, inhibits oxygen diffusion into the coating. Because of the increasing interest in this refractory material in thin layers and to provide a better understanding, it would be desirable to have data on its oxidation behaviour.

AlN films have been grown by various methods such as the chemical vapour deposition (CVD) process, ${ }^{12,13}$ reactive molecular beam epitaxy (MBE),${ }^{14}$ ion beam sputtering, ${ }^{15}$ ion nitriding, etc. Recently, amorphous AlN thin films have been deposited at reasonably low temperatures $\left(300-800^{\circ} \mathrm{C}\right)$, by metal-organic plasma enhanced chemical vapour deposition (MOPECVD)., ${ }^{76}$ Hasegawa et al. ${ }^{16}$ investigated the possibility and conditions of deposition. The present authors use these conditions to determine certain deposition parameters such as radiofrequency (RF) power density, the substrate temperature, the choice of carrier and precursor gas, and the $\mathrm{NH}_{3} / \mathrm{TMA}$ ratio. In this way, AlN thin films, with an oriented (100) structure, have been obtained on silicon (100) wafers. This original result differs from Hasegawa's previous papers, especially by the excitation frequency.

Thermal oxidation of these samples has been studied in air from $500^{\circ} \mathrm{C}$ to $1300^{\circ} \mathrm{C}$ by different methods of analysis. The film characteristics are investigated by scanning electron microscopy (SEM) and X-ray diffraction, and the elemental composition of the films is examined by Auger electron spectroscopy (AES), to determine the oxygen progress in the layer. On the other hand, infra-red absorption spectroscopy is a useful and nondestructive method to study the results of the heat treatment because of its sensitivity to changes in the external environment of the vibrating group.

\section{Experimental}

\subsection{Deposition system}

Figure 1 shows the schematic arrangement of the experimental tubular hot wall reactor. A parallel electrodes plasma CVD system is employed for this study. A $440 \mathrm{kHz}$ generator is used to supply RF power which is capacitively coupled to the system. The silicon (100) substrate temperature is kept at $330^{\circ} \mathrm{C}$. Trimethylaluminium (TMA), with nitrogen carrier gas (nitrogen, 5.0 purity of $99.999 \%$ ), is introduced between the electrodes from a different gas line ${ }^{16}$ than the ammonia (ammonia, $4 \cdot 5$, purity of

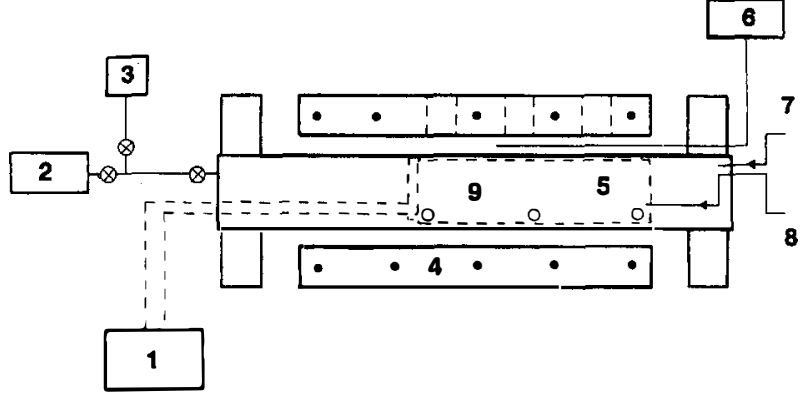

Fig. 1. Schematic representation of horizontal tube reactor used in this plasma CVD system: 1, RF power supply; 2, pump; 3 , pressure control; 4 , oven; 5 , electrodes; 6 , oven temperature control; 7, ammonia precursor; 8, TMA and nitrogen carrier gas; 9 , samples.

$99.995 \%$ ). The background pressure of the system is around $0.9 \mathrm{~Pa}$. The other synthesis conditions are a RF power density of $0.26 \mathrm{~W} \mathrm{~cm}^{-2}$, a total pressure of $7 \mathrm{~Pa}$, the aluminium precursor bubbler temperature around $55^{\circ} \mathrm{C}$, and the $\mathrm{NH}_{3} / \mathrm{TMA}$ ratio above 5 .

AlN films are successfully obtained from this reactive system in a plasma atmosphere with a deposition rate about $1 \mu \mathrm{m} / \mathrm{h}$, whereas it is impossible under thermodynamical equilibrium conditions at $330^{\circ} \mathrm{C}$ (in thermal CVD conditions, for example, $1200^{\circ} \mathrm{C}$ in Ref. 13).

\subsection{Film characteristics}

Scanning electron micrographs show uniform, dense AlN coatings with an excellent adherence and a very good step coverage on a wide variety of substrates (polished silicon wafers, graphite substrate or polycrystalline sintered silicon carbide), as can be seen in Figs 2 and 3. The surface shows a low defect density.

The refractive index, measured by ellipsometry, changes between $2 \cdot 0$ and $2 \cdot 2$ at the $5461 \AA$ wavelength. These values are close to the reported values for crystalline $\mathrm{AlN}$ (2.17 for single-crystal AlN for a wavelength of $5890 \AA^{17}$ ).

The X-ray diffraction pattern shows AlN coatings having a (100) preferential orientation (ASTM Data Card No. 25-1134), which is not influenced by the substrate: the same results are observed on silicon (111) or (100), silicon carbide and glass plates. On the other hand, the excitation frequency has an influence upon the material crystallinity: in a low-frequency field $(440 \mathrm{kHz})$, AlN thin films are oriented along the $a$-axis, whereas in a high-frequency field $(13.56 \mathrm{MHz})$ the material is amorphous. ${ }^{16}$

The surface ionic bombardment is an important parameter which influences adhesion, density, structure and stress $^{18}$ of plasma deposits. The 


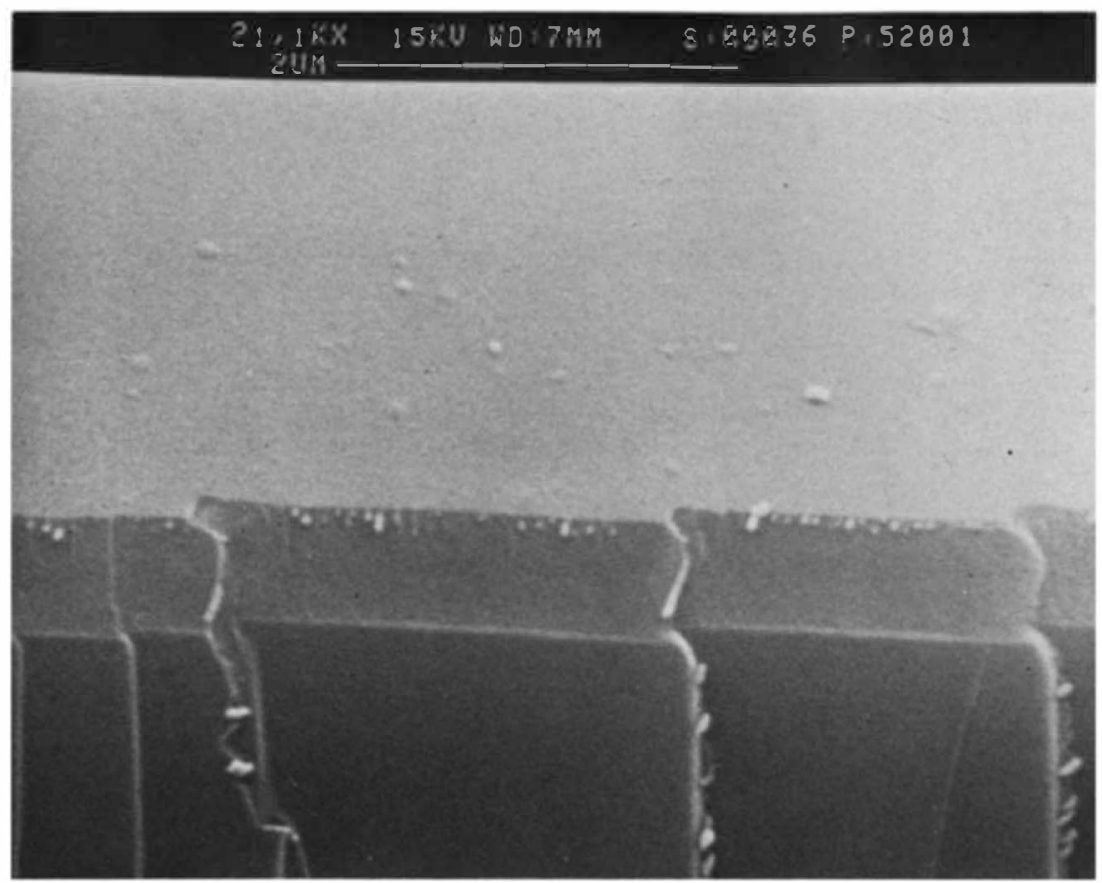

Fig. 2. AlN coating on silicon (100) substrate. The cracks are uninterrupted from substrate to the layer. energetic particles inherent to the process cause intrinsic stresses in the coating which can be modulated principally by the excitation frequency. ${ }^{19}$ In this paper, intrinsic stresses are measured using the interference technique ${ }^{20}$ with a thallium lamp. The measurement indicates tensile stresses in AlN $(+268 \mathrm{MPa})$ obtained at a $440 \mathrm{kHz}$ frequency. This value does not change up to $550^{\circ} \mathrm{C}$.

Generally, in the plasma deposition process, the end products are realised with few impurities. This is just a function of the purity of the precursor gas, the gas delivery system and the reactor itself. Thereby, the deposited films composition, measured by AES, reveals a percentage of carbon lower than $5 \%$. No oxygen is detected $(<1 \%)$, as can be seen in Fig. 4 .

IR spectra of AlN deposited on silicon (100) wafers were taken using a Nicolet Fourier transform infra-red spectrometer (model 5ZDX). They show a broad, single strong peak at $670 \mathrm{~cm}^{-1}$ associated with the transverse optical vibration mode. Two other absorption-band areas have also been identified in Fig. 5: $\mathrm{N}-\mathrm{H}\left(3205 \mathrm{~cm}^{-1}\right)$ and $\mathrm{Al}-\mathrm{H}$ $\left(2108 \mathrm{~cm}^{-1}\right)$, the hydrogen source in the film being the ammonia or TMA reactants.

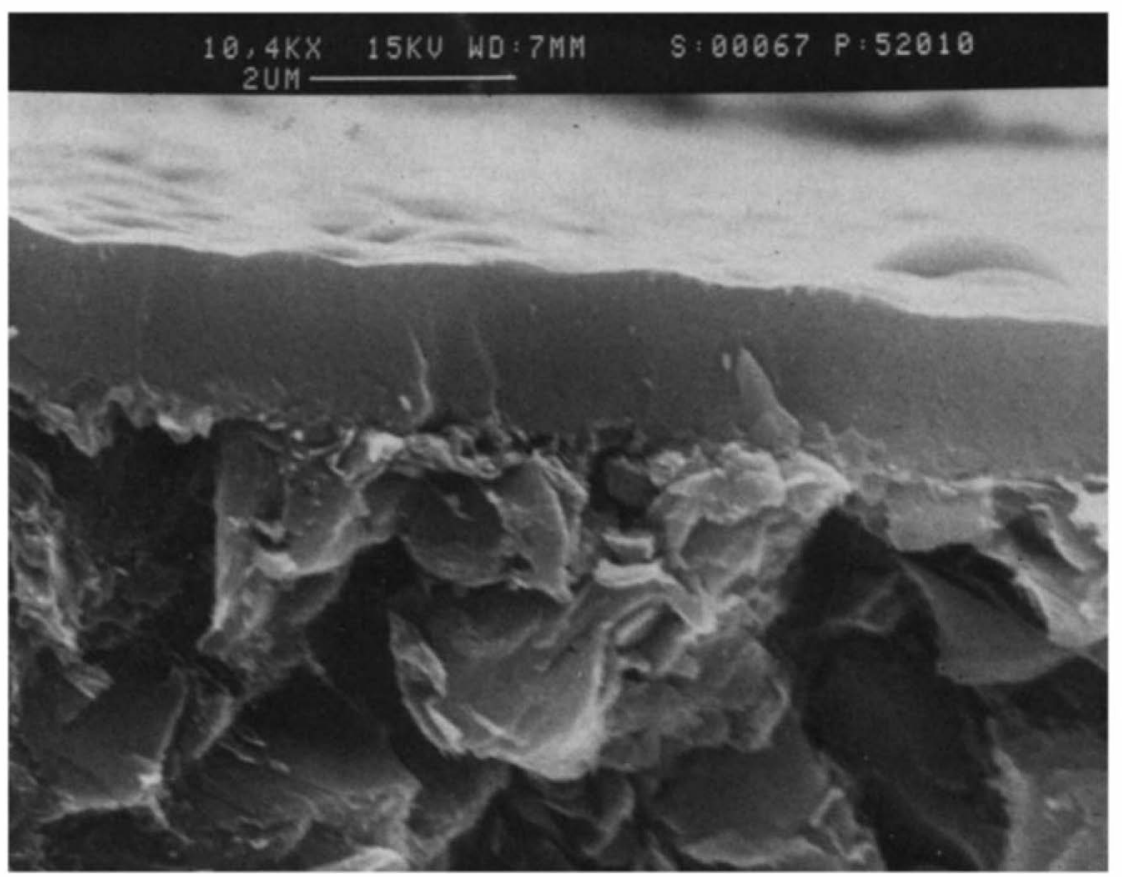

Fig. 3. Good step coverage of the AlN coating on graphite substate. 


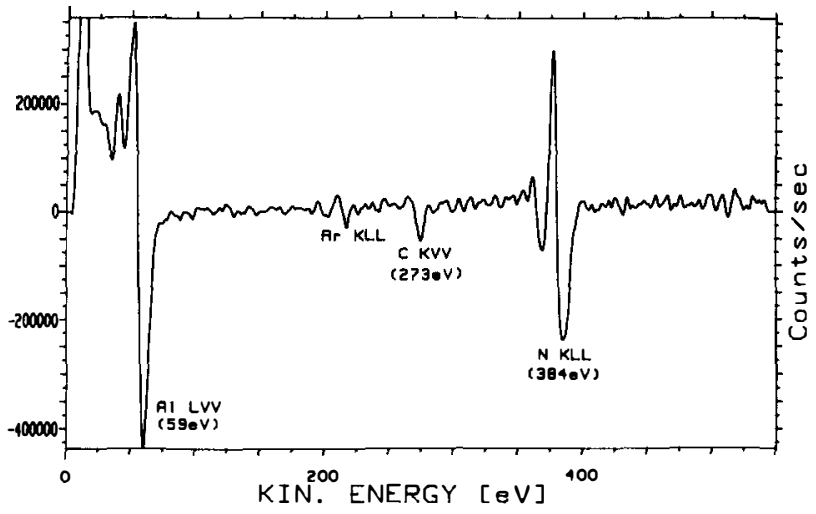

Fig. 4. d/de[E. N(E)] Auger electron energies spectra of AIN obtained by PECVD.

\section{Oxidation of Aluminium Nitride Coatings}

In this work, AlN thin films $(2 \mu \mathrm{m})$ deposited on silicon (100) were used. AlN samples in air are placed in the oven (the oven is kept open during treatments). Treatment temperatures are raised to the desired point at the rate of $150^{\circ} \mathrm{C} / \mathrm{h}$, kept constant for $45 \mathrm{~min}$, and decreased to ambient temperature at the rate of $100^{\circ} \mathrm{C} / \mathrm{h}$.

\subsection{X-Ray, SEM}

The oxidation stages are first observed from X-ray diffraction data between $300^{\circ} \mathrm{C}$ and $1300^{\circ} \mathrm{C}$. Up to $900^{\circ} \mathrm{C}$ only AlN (100) peaks are observed. The formation of an amorphous phase at $1000^{\circ} \mathrm{C}$ is indicated by the complete disappearance of all peaks. At $1100^{\circ} \mathrm{C}$ only $\alpha-\mathrm{Al}_{2} \mathrm{O}_{3}$ peaks are observed (Fig. 6).

Comparing this result to cross-section SEM micrographs, three different textures of coatings are observed (Figs 7-10). At the formation temperature

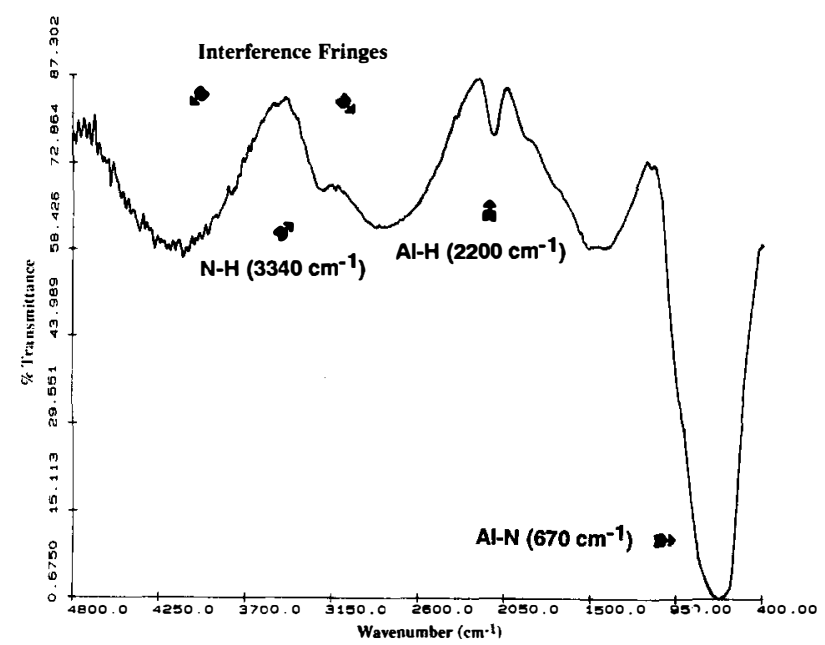

Fig. 5. Infra-red spectrum of AIN thin film deposited on silicon (100) wafers, with a thickness of $2 \mu \mathrm{m}$. (The silicon spectrum has been subtracted.)
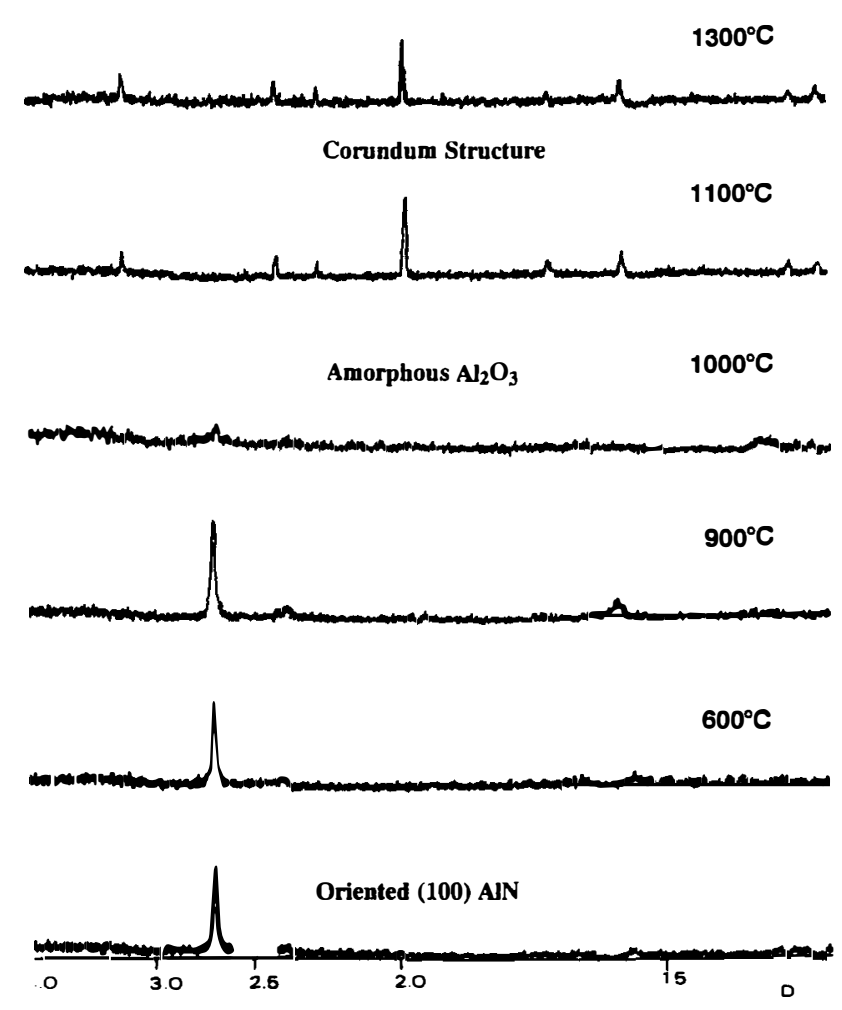

Fig. 6. Crystalline AIN transformation into a corundum structure shown by the X-ray diffraction pattern.

$\left(330^{\circ} \mathrm{C}\right)$ and up to $800^{\circ} \mathrm{C}$, the film is dense with a slightly columnar texture. During the heat treatments, two texture changes occur, resulting in granular and porous textures at $900^{\circ} \mathrm{C}$ and $1100^{\circ} \mathrm{C}$, respectively. These correspond to the amorphous $\mathrm{Al}_{2} \mathrm{O}_{3}$ and the crystalline $\alpha$-alumina formation known from sintered aluminium nitride, ${ }^{10}$ as shown by AES measurements (see Section 3.3).

\subsection{Infra-red absorption spectroscopy}

The oxidation of aluminium nitride samples starts at temperatures around $900^{\circ} \mathrm{C}$. The refractive index is commonly measured by ellipsometry to determine the quality and the reproducibility of the plasma deposited films. For the thick samples $(>1 \mu \mathrm{m})$, interference fringes pattern of IR spectra are used to determine the thickness $d$, or the refractive index $n$, of the films at the normal incidence angle. ${ }^{21}$ The refractive index can be calculated by measuring the wavenumber difference between two minima or maxima of interference fringes according to the equation:

$$
n=\Delta m / 2 d \Delta v_{\mathrm{if}}
$$

where $\Delta m=m_{\mathrm{i}}-m_{\mathrm{f}}$ is the fringes number between the initial and final fringes, and $\Delta v_{i f}=v_{\mathrm{i}}-v_{\mathrm{f}}$ is the wavenumber difference between the initial and final fringes. For the best estimation, $\Delta v_{\text {if }}$ has been calculated from $4750 \mathrm{~cm}^{-1}$ to $1150 \mathrm{~cm}^{-1}$. In this 


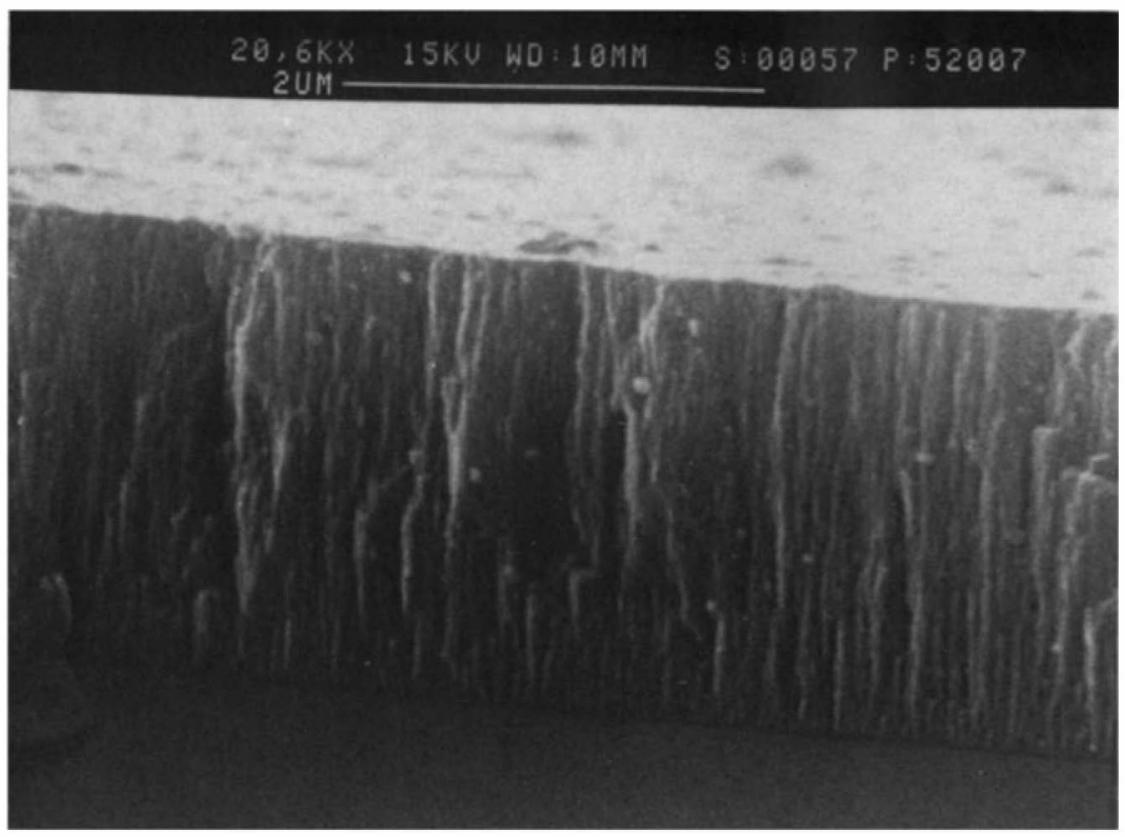

Fig. 7. AlN dense coating with a columnar texture synthesised at a temperature of $330^{\circ} \mathrm{C}$. This texture is observed from $330^{\circ} \mathrm{C}$ to $800^{\circ} \mathrm{C}$.

range of wavenumbers, only the $\mathrm{N}-\mathrm{H}$ and $\mathrm{Al}-\mathrm{H}$ weak band vibrations are observed; thus, the fringes are not disturbed.

In Fig. 11, high values of the refractive index are due to aluminium nitride, ${ }^{16}$ and the low values, to alumina. ${ }^{22}$ This diagram is in good agreement with $\mathrm{X}$-ray and SEM data. The untreated film has a lower index values which may indicate impurities or a structural disorder.

The plasma-deposited materials often contain hydrogen as $\mathrm{Si}_{x} \mathrm{~N}_{y}: \mathrm{H},{ }^{23} \mathrm{Si}_{1-x} \mathrm{C}_{x}: \mathrm{H}^{24}$ or similar adducts. Precursor gas dissociation produces a greater amount of hydrogen which can be trapped in the growing films. In the present work, hydrogen bonded to an aluminium atom is used as a probe of the presence of oxygen in thin films. It is known that the concept of localised group frequencies is modified by many other factors, and the results of these determine the precise position of the absorption band. Some of them are: changes of state, mass and coupling effects, strain and electrical effects. The last term can be considered as the most important in the present case (especially the inductive effects).

Figure 12(a) shows the oxygen influence on the $\mathrm{Al}-\mathrm{H}$ bond vibration frequency. The model in Fig. 12(b) permits a good understanding of the pheno-

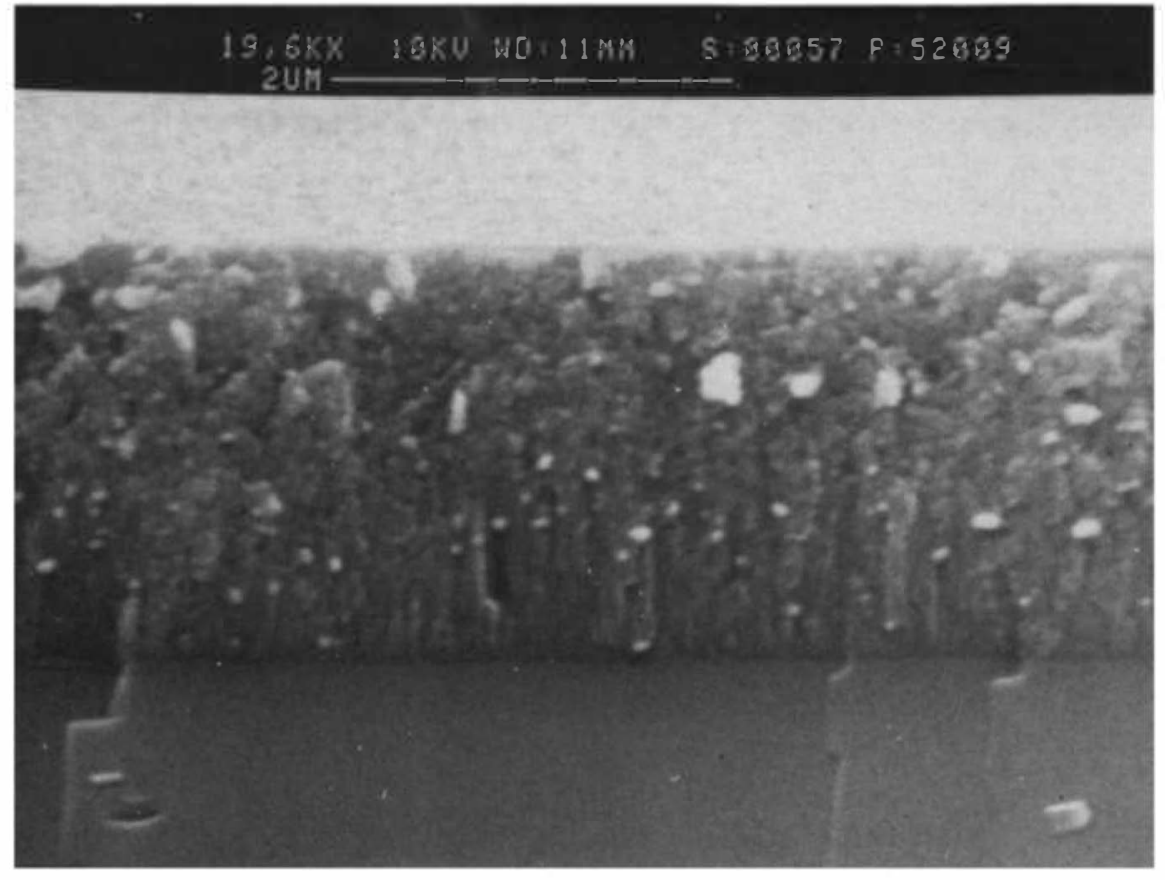

Fig. 8. Granular texture of amorphous $\mathrm{Al}_{2} \mathrm{O}_{3}$ and columnar texture of $\mathrm{AlN}$, from $900^{\circ} \mathrm{C}$ to $1000^{\circ} \mathrm{C}$. 
Fig. 9. Porous and granular textures of crystallised and amorphous alumina at $1100^{\circ} \mathrm{C}$.

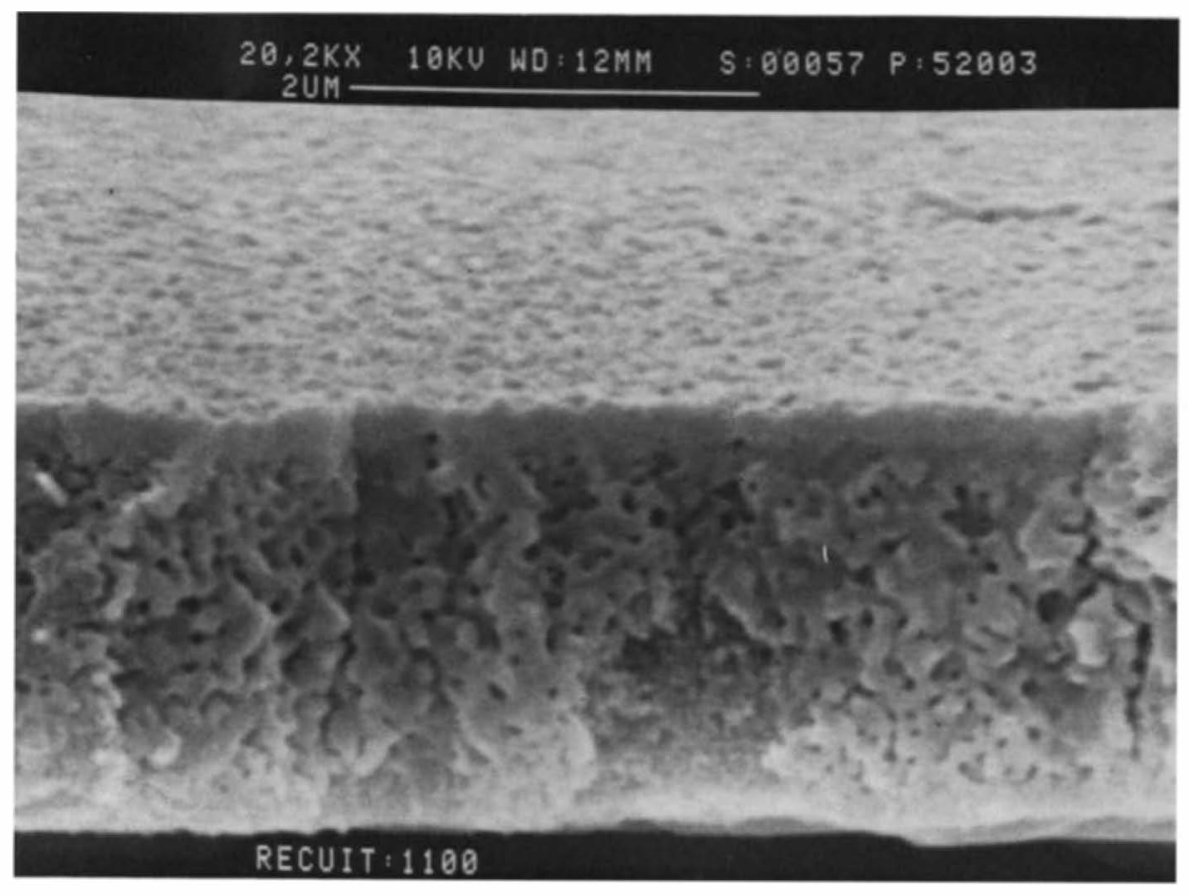

phases: the first band corresponds to the nontransformed AlN and the other to an oxynitride phase.

\subsection{Auger electron spectroscopy}

The sample Auger electrons are analysed by a Riber MAC-2 Auger spectrometer. The AES measurements are taken at different ionic sputtering times for every sample; parameters such as the primary electron energy of the beam, the gun electron emission current and the energy ionic sputtering are kept constant. The sputtering rate is about 30 to

Fig. 10. Porous texture of $\alpha$-alumina from $1200^{\circ} \mathrm{C}$ to $1300^{\circ} \mathrm{C}$

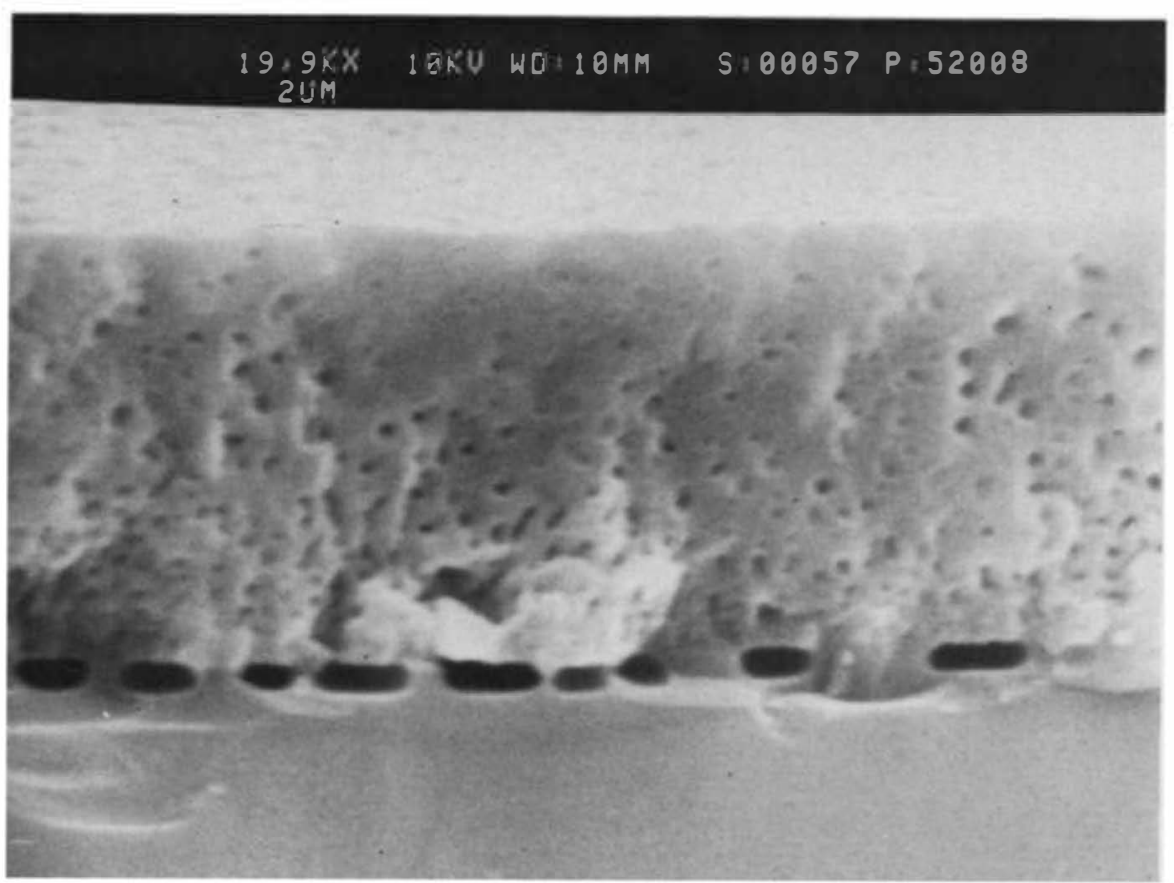




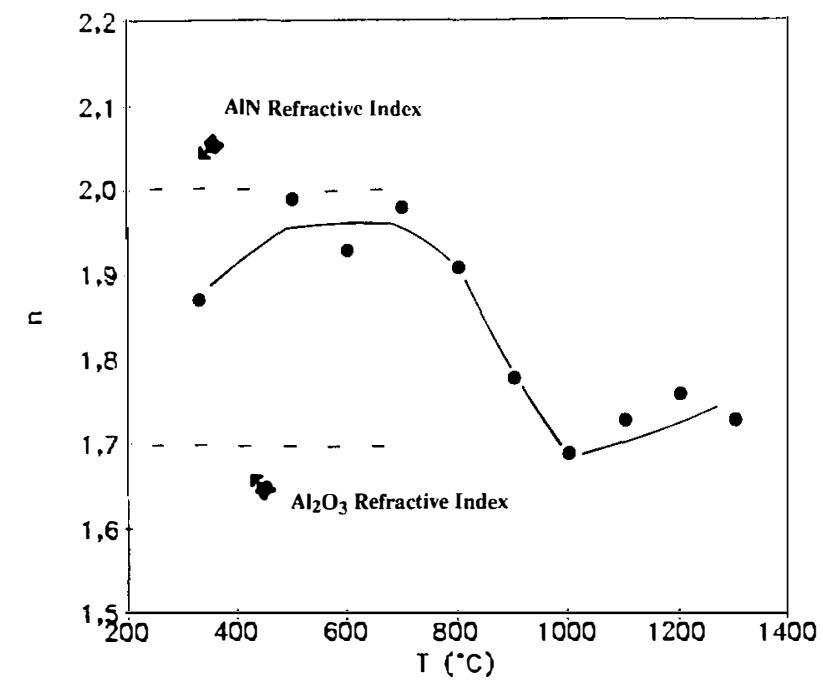

Fig. 11. Refractive index variation according to temperature treatments. The refractive index is obtained from the interference fringes pattern of IR spectra.

$50 \AA / \mathrm{min}$. The authors were interested in the oxygen concentration profiles in the AlN coating annealings. They have been obtained from the product of the kinetic energy by the number of collected elections having this energy E.N(E) Auger spectra, scanned in the range between 50 and $520 \mathrm{eV}$. The intensity of the KLL Auger transition for the oxygen atom (OKLL) at $510 \mathrm{eV}$ has been determined by measuring heights of the peak with respect to the level of the background. ${ }^{25}$

The results of the peak to background ratio $(\mathrm{P} / \mathrm{B})$ variation versus sputtering time shown in Fig. 13 are in good agreement with the previous studies. The initial stage of oxidation is the oxide formation on the surface $(100-200 \AA)$. The 300,600 and $700^{\circ} \mathrm{C}$ curves show a decrease to negligible values of the oxygen. The $\mathrm{P} / \mathrm{B}$ are significant of a gradual $\mathrm{AlO}_{x} \mathrm{~N}_{y}$ intermediate area rather than alumina, between the native oxide layer and the nitride remaining. This oxynitride layer has a thickness which is not greater than $1000 \AA$. Up to $900^{\circ} \mathrm{C}$ the $\mathrm{P} / \mathrm{B}$ values are constant and correspond to alumina. In this case, the sputtering conditions have not permitted the hollowing out of the coating to reveal the aluminium oxynitride and the nitride observed at $900^{\circ} \mathrm{C}$ by IR. Beyond $900^{\circ} \mathrm{C}$ a thick alumina coating is formed.

\section{Conclusion}

For the first time, aluminium nitride thin films obtained by the MOPECVD process have a (100) crystalline orientation. The coatings are dense, adherent and show a good step coverage and few impurity incorporations. Their oxidation behaviour

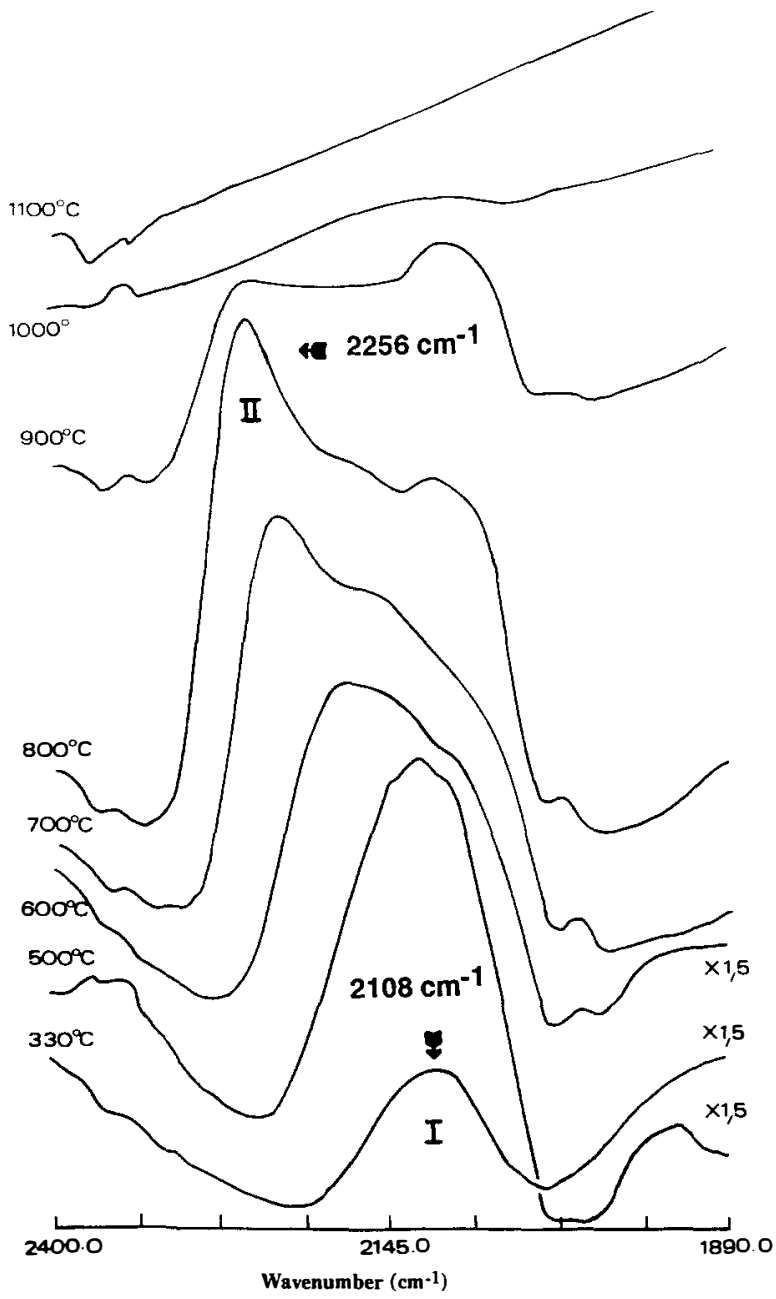

Fig. 12. (a) Effect of aluminium environment on $\mathrm{Al}-\mathrm{H}$ bond vibration frequency.<smiles>[1H][Al](N)(N)N([14CH3])[14CH3]</smiles>

Fig. 12. (b) Model showing the nitrogen substitution by oxygen. The polar character of the $\mathrm{Al}-\mathrm{H}$ vibration bond decreases and also the vibration frequency increases.

is identical to AIN powders. X-Ray diffraction, SEM and AES show two transformations at $900^{\circ} \mathrm{C}$ and $1100^{\circ} \mathrm{C}$ which correspond respectively to the $\mathrm{AlN}$ transformation into amorphous $\mathrm{Al}_{2} \mathrm{O}_{3}$, and the amorphous phase into the corundum structure. Nevertheless, by the study of the $\mathrm{Al}-\mathrm{H}$ vibrating band shift, IR spectroscopy reveals that the oxidation of AlN thin films starts at $600^{\circ} \mathrm{C}$. The formation of an oxynitride layer between the aluminium nitride and alumina is observed. The alumina coating is amorphous at $1000^{\circ} \mathrm{C}$ and crystallises at $1100^{\circ} \mathrm{C}$ in $\alpha-\mathrm{Al}_{2} \mathrm{O}_{3}$.

This work is just a step towards coatings for antioxidation protection at high temperatures. The use 


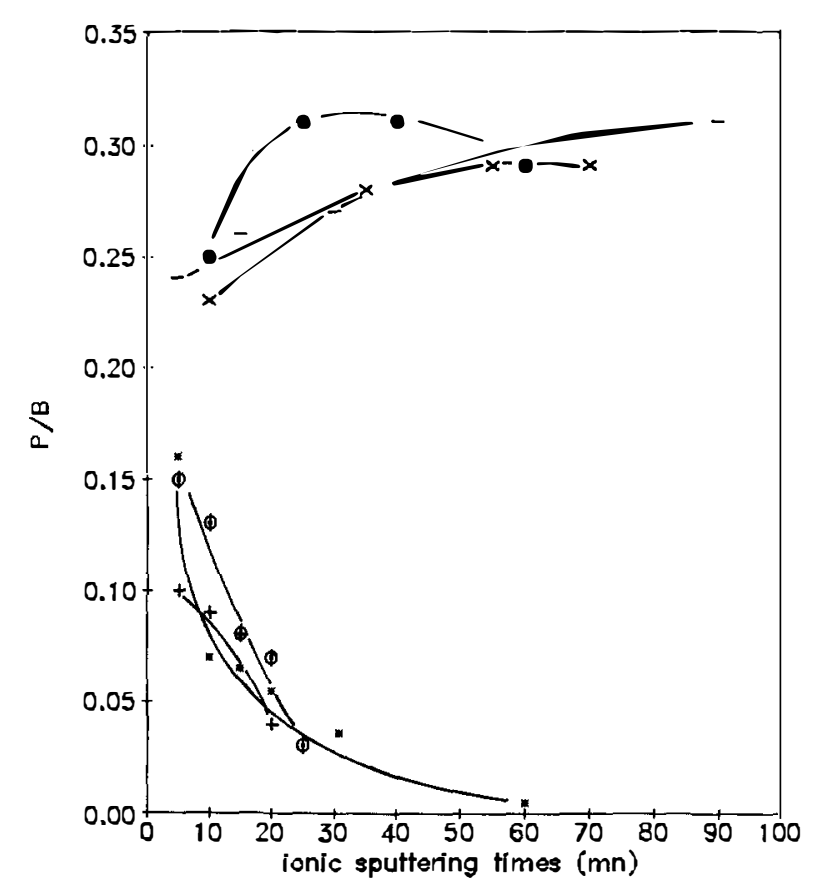

Fig. 13. Oxygen concentration-depth profile at different temperature treatments obtained from the AES spectra. $\Phi$, $300^{\circ} \mathrm{C} ;+, 600^{\circ} \mathrm{C} ; *, 700^{\circ} \mathrm{C} ; 0,900^{\circ} \mathrm{C} ; \times, 1000^{\circ} \mathrm{C} ;-, 1100^{\circ} \mathrm{C}$.

of multilayers or gradual layers, which include AlN coating(s), might be a better way to stop oxygen diffusion.

\section{References}

1. Yim, W. M., Stofko, E. J., Zanzucchi, P. J., Pankove, J. I., Ettenberg, M. \& Gilbert, S. L., Epitaxially grown AIN and its optical band gap. J. Appl. Phy's., 44 (1973) 292-6.

2. Bauer, J., Biste, L. \& Bolze, D., Optical properties of aluminium nitride prepared by chemical and plasmachemical vapour deposition. Phy's. Stat. Sol. (a), 39 (1977) 173-8!.

3. Kurokawa, Y., Utsumi, K., Takamisawa, H., Kamata, T. \& Noguchi, S., AlN substrates with high thermal conductivity. IEEE Transactions on Components, Hybrids and Manufacturing Technology, CHMT-8 (1985) 247-52.

4. Feil, M., Experience with AIN substrate. Hybrid Circuits, 18 (1989) 29-34.

5. Dobrynin, A. V., Naida, G. A. \& Novoselov, V. A., Acoustoelectric parameters of aluminium nitride epitaxial layers. Phys. Stat. Sol. (a), 104 (1987) K47-K51.

6. Lewis, D. W., Properties of aluminum nitride derived from $\mathrm{AlCl}_{3} . \mathrm{NH}_{3}$. J. Electrochem. Soc., 117 (1970) 978-82.

7. Itoh, H., Kato, M. \& Sugiyama, K., Plasma-enhanced chemical vapour deposition of AlN coatings on graphite substrates. Thin Solid Films, 146 (1987) 255-64.

8. Abid, A., Bensalem, R. \& Sealy, B. J., The thermal stability of AlN. J. Mat. Sci., 21 (1986) 1301-4.

9. Hatwar, T. K. \& Pian, T. R., Surface studies of aluminium nitride thin films. Mat. Res. Soc. Symp. Proc., 121 (1988) 557-60.

10. Lavrenko, V. A. \& Alexeev, A. F., Oxidation of sintered aluminium nitride. Ceramics International, 9 (1983) 80-2.

11. Katnani, A. D. \& Papathomas, K. I., Kinetics and initial stages of oxidation of aluminum nitride: thermogravimetric analysis and X-ray photoelectron spectroscopy study. $J$. Vac. Sci. Technol., A5 (1987) 1335-40.

12. Pauleau, Y., Bouteville, A., Hantzpergue, J. J. \& Remy, J. C., Composition, kinetics, and mechanism of growth of chemical vapor-deposited aluminum nitride films. $J$. Electrochem. Soc., 129 (1982) 1045-52.

13. Morita, M., Uesugi, N., Isogai, S., Tsubouchi, K. \& Mikoshiba, N., Epitaxial growth of aluminum nitride on sapphire using metalorganic chemical vapor deposition. Japan. J. Appl. Phys., 20 (1980) 17-23.

14. Yoshida, S., Misawa, S., Fujii, Y., Takada, S., Hayakawa, H., Gonda, S. \& Itoh, A., Reactive molecular beam epitaxy of aluminium nitride. J. Vac. Sci. Technol., 16 (1979) 990-3.

15. Dehuang, W., Sputtered AIN films for semiconductor lasers. Thin Solid Films, 187 (1990) 127-32.

16. Hasegawa, F., Takahashi, T., Kubo, K. \& Nannichi, Y. Plasma CVD of amorphous AIN from metalorganic $\mathrm{Al}$ source and properties of the deposited films. Japan. J. Appl. Phy's., 26 (1987) 1555-60.

17. Pastrnak, J. \& Roskovcova, L., Refraction index measurements on AlN single crystals. Phy's. Stat. Sol. (a), 14 (1966) K5-K8.

18. Catherine, Y., Croissance de couches minces sous flux d'ions. In Journées d'études: Interaction plasmas froids matériaux, Oléron (1987). Editeur Scientifique, GRECO 57-Editions de physique, Paris, 319-39.

19. Hess, D. W., Plasma-enhanced CVD: Oxides, nitrides, transition metals, and transition metal silicides. J. Vac. Sci. Technol., A2 (1984) 244-52.

20. Finegan, J. D. \& Hoffman, R. W., Stress and stress anisotropy in iron films. In Trans. 8th Natl Vacuum Symp. Pergamon Press, New York, 1961, pp. 935-42.

21. Harrick, N. J., Determination of refractive index and film thickness from interference fringes. Applied Optics, 10 (1971) 2344-9.

22. Schemmel, T. D., Cunningham, R. L. \& Randhawa, H., Process for high rate deposition of $\mathrm{Al}_{2} \mathrm{O}_{3}$. Thin Solid Films, 181 (1989) 597-601.

23. Wang, S. L., Cheng, R. G., Qi, M. W. \& Cai, P. X., IR and H evolution spectrum of $\alpha-\mathrm{SiN}_{x}: \mathrm{H}$ with different nitrogen content. J. Non-Cry'st. Sol., 97-98 (1987) 1039-42.

24. Basa, D. K. \& Smith, F. W., Annealing and crystallization processes in a hydrogenated amorphous $\mathrm{Si}-\mathrm{C}$ alloy film. Thin Solid Films, 192 (1990) 121-33.

25. Langeron, J. P., Minel, L., Vignes, J. L., Bouquet, S., Pellerin, F., Lorang, G., Ailloud, P. \& Le Héricy, J., The use of peak to background ratio in quantitative Auger analysis. Solid State Communication, 49 (1984) 405-7. 